\title{
La publicidad de las normas en nuestro ordenamiento jurídico. Especial referencia a la publicación de actos y acuerdos de las Corporaciones locales en los Diarios oficiales de las provincias
}

\author{
Francisco-Javier Jiménez Lechuga \\ Doctor en Derecho, Profesor del Instituto Andaluz de Administración Pública (IAAP) y \\ Secretario de Administración Local. Abogado
}

Sumario: I. INTRODUCCIÓN. II. SANCIÓN, PROMULGACIÓN Y PUBLICACIÓN DE LAS NORMAS. III. NOTIFICACIÓN Y PUBLICACIÓN DE LOS ACTOS ADMINISTRATIVOS EN NUESTRO ORDENAMIENTO JURÍDICO CON ESPECIAL REFERENCIA A LA ADMINISTRACIÓN LOCAL. IV. LA NUEVA REGULACIÓN DE LA PUBLICACIÓN DE ACTOS Y ACUERDOS DE LAS CORPORACIONES LOCALES: LOS DIARIOS OFICIALES DE LAS PROVINCIAS. V. CONCLUSIONES. VI. BIBLIOGRAFÍA.

\section{INTRODUCCIÓN}

Es mucho lo que se ha elucubrado a lo largo de los siglos en torno a la validez del Derecho. A ello aludiré prima facie brevemente enseguida. Pero lo que interesa es conocer el alcance y contenido en nuestro ordenamiento jurídico de los artículos 9.3 y 91 de la Constitución, en relación con el artículo 2 del Código Civil y el artículo 22 y siguientes de la Ley 50/1997, de 27 de noviembre, del Gobierno. Porque perece claro que las normas jurídicas deben trascender a su autor, de manera que puedan ser conocidas por todos sus destinatarios en aras del principio de legalidad, el de publicación de las normas y el de seguridad jurídica, como es natural. Difícilmente puede exigirse a nadie el cumplimiento de una norma o disposición legal que permanece oculta o no ha sido sancionada, promulgada y publicada debidamente. Sin la publicación de las leyes, ciertamente, éstas no pueden entrar en vigor en forma alguna (otra cosa es el llamado plazo de entrada en vigor o vacatio legis). Otra cosa es que la presunción de conocimiento por los ciudadanos de las leyes (artículo 6.1C.c.) pueda mantenerse con seriedad y rigor. En este sentido —analizando el fenómeno de la llamada por O. SchMitT la legislación «motorizada» y, en relación con las tesis de J. ORtega y Gasset ha escrito recientemente el profesor 
E. GARCía de ENTERRÍA ${ }^{1}$ que tal exigencia se nos antoja hoy como un sarcasmo, pues no hay persona alguna, incluyendo a los juristas más cualificados, que pueda pretender hoy conocer una minúscula fracción apenas de esa marea inundatoria e incesante de leyes y reglamentos entre cuyas complejas mallas hemos, no obstante, de vivir. Esta «legislación incontinente» a la que también se refiere ORTEGA Y GASSET como he indicado, la expresa el mismo diciendo que la legislación se ha hecho cada vez más fecunda, y en los últimos tiempos se ha convertido en una ametralladora que dispara leyes sin cesar. Esto trae consigo que el individuo no pueda proyectar su vida, la legislación incontinente le desencaja de sí mismo, le impide ser; - y sigue diciendo más adelante- se ha establecido la tendencia natural en el Estado a reglamentarlo todo, aunque la situación de peligro haya desaparecido lo que trae consigo que se perpetúe esa impresión de peligro y que el individuo se sienta constantemente como el personaje de Kafka ${ }^{2}$, reo de no sabe que posibles delitos ${ }^{3}$.

Antes de continuar con estas reflexiones quiero detenerme brevemente en el concepto de validez del Derecho. Hay que distinguir entre validez material (justicia del Derecho), validez formal (existencia del Derecho) y validez sociológica (obediencia al Derecho). Desde el primer aspecto nos movemos desde las tesis del valor, de la idealidad (Sein Sollende). Estamos ante una dimensión axiológica, espiritual y emocional de lo jurídico, en su proyección deontológica y filosófica, la cual es objeto del estudio del filósofo propiamente dicho. Aquí se plantea la duda de si el Derecho es o no justo, variando la respuesta según que la facilite un positivista o un iusnaturalista. Para los primeros la justicia o legitimidad, en definitiva, la armonía con el Derecho natural, es una nota que sólo se requiere para que la norma sea justa, pero no para que sea Derecho positivo. Contrariamente, los iusnaturalistas estiman que se requiere en todo caso, pues una norma injusta no es válida y por tanto no existe como tal Derecho ${ }^{4}$.

\footnotetext{
${ }^{1}$ E. García de Enterría, Jueces y seguridad jurídica en un mundo de leyes desbocados, Ed. Civitas, Madrid, 1999.

${ }^{2}$ Por cierto que Kafka, que es como se apellidaba este extraordinario escritor, en checo es «Kavka», lo que significa grajo o cuervo. Lo digo como simple curiosidad y no movido por una pedantería inaceptable. Lo sé porque he vuelto a leer recientemente El proceso, y lo decía el traductor. La edición me parece que es de Alianza Editorial, pero al no tenerlo ahora a la vista, no puedo asegurarlo. La sólida formación de los lectores de esta revista — hecho éste que me consta fehacientemente- suplirá con creces mi flaca memoria y torpe manejo de las fuentes.

${ }^{3}$ E. GARCía de EnTERRía, Jueces y seguridad jurídica en un mendo de leyes desbocados, Ed. Civitas, Madrid, 1999.

${ }^{4}$ M. Albaladejo, Derecho civil, Ed. Bosch, Barcelona, 1989 y H. Kelsen, Teoría general del Estado y del Derecho, México, 1983.
} 
Desde un punto de vista formal (existencia del Derecho), son necesarias según la doctrina tres condiciones para que una norma dada sea válida. La primera es que la misma haya sido promulgada en forma adecuada, es decir, por el órgano competente y con arreglo al procedimiento establecido al efecto. Es menester, además, que dicha norma jurídica no haya sido derogada bien en la forma prevista por el ordenamiento jurídico, bien por el hecho de que el ordenamiento jurídico como un todo haya dejado de ser eficaz $^{5}$, bien por desuso o desuetudo ${ }^{6}$, cuando por un período de tiempo considerable y de manera permanente la norma ha dejado de ser efectiva, a modo de norma negativa. Finalmente, se exige que la norma no sea contradictoria con otra norma válida del sistema sin haber forma de resolver la antinomia con arreglo a los criterios normales de jerarquía, cronológico, de especialidad y de competencia ${ }^{7}$.

Me interesa destacar, como ha hecho algún otro autor, que como excepción dentro del positivismo jurídico en la equiparación entre validez y existencia de la norma parecería a primera vista que se encuentra el pensamiento de $\mathrm{HART}^{8}$, para el cual hay una norma o regla, para utilizar la terminología de HART, la «regla de reconocimiento», que existe y de la que no cabe predicar su validez o invalidez, sino que es simplemente aceptada como apropiada para ser usada como criterio de identificación de las demás normas del sistema ${ }^{9}$.

En cuanto a la validez sociológica (obediencia al Derecho), se mueve en el plano empírico fáctico del ser, de los hechos, de la realidad, del Sein $\mathrm{o}$ is regido por el principio de causalidad y necesidad ${ }^{10}$. El estudio de esta dimensión del fenómeno jurídico corresponde el sociológico que ha de tener como objeto ${ }^{11}$ de trabajo la naturaleza, más en concreto la práctica

\footnotetext{
5 J.W. HARRIS, Law end legal science. An inquiry into the concepts «legal rule» and «legal system», Clarendon Press, Oxford, 1979.

${ }^{6}$ E. Pattaro, Filosofía del Derecho. Derecho, Ciencia jurídica, Ed. Reus, Madrid, 1980.

${ }^{7}$ N. Álvarez, «Reflexiones en torno al concepto de validez jurídica», Revista de la Facultad de Derecho de la Universidad Complutense de Madrid, núm. 56/1979.

${ }^{8}$ H.L.A. HART, «Bentham and the demythification of the Law», en Modern Law Review, 1993.

${ }^{9}$ E. Garzón Valdés, Algunos modelos de validez normativo, México, 1980 y E. CAssirer, El mito del Estado, Fondo de Cultura Económica, México, 1974.

${ }^{10}$ M. ${ }^{a}$ J. Falcón Tella, El concepto y fundamento de la validez del Derecho, Ed. Civitas, Madrid, 1994.

11 J. Delgado Pinto, La validez del Derecho como problema en la Filosofía jurídica, México, 1980.
} 
judicial ${ }^{12}$. A esta labor va unidad una teoría o concepción del Derecho, ya no iunaturalista ni positivista, sino realista. Se trata de abarcar el aspecto ontológico y fenomenológico de la validez, es decir, su eficacia ${ }^{13}$.

Ha apuntado recientemente algún autor respecto de este aspecto sociológico del Derecho que, en lo que se refiere a su validez empírica, fáctica o sociológica en la esfera del Sein, destaca la aportación de M. Weber, según la cual para dicha validez lo decisivo es la «orientación» del actuar en base a un ordenamiento y no su «observacia». Y señala «graduaciones» en la escala de la obediencia. En el caso de que la elusión y la infracción del sentido aceptado como promedio de un ordenamiento se haya convertido en regla, entonces el ordenamiento vale sólo en una medida limitado, o bien no vale en absoluto. Así, entre la validez y la no validez de determinado ordenamiento no existe para la sociología, como existe sin embargo para el Derecho, dada su finalidad, una alternativa absoluta. Existen, por el contrario, pasos inciertos entre ambos casos. Esto que ocurre con los ordenamientos jurídicos, como conjunto de normas, es válido también para una norma aislada. Otra diferencia de la validez empírica y de la validez jurídica o para el jurista (que Max WeBer llamó validez ideal con una significación no equiparable a la aquí empleada para ese terminología) ${ }^{14}$ sería que en aquélla el cumplimiento y la ejecución coactiva de la norma son sólo la consecuencia de un comportamiento, mientras que en la validez jurídica serían su esencia ${ }^{15}$.

La teoría de la ley y de la validez del Derecho no es única, sino que existen varias. Así, destacan — por no remontarnos a épocas muy lejanas- las tesis de Santo Tomás DE AQUINo con su conocido iusnaturalismo (intelectualista, formalista, realista y cristiano), el iusnaturalismo realista de F. SuÁrez (análisis de De legibus), el voluntarismo o subjetivismo jurídico (contrato social y principio de pacta sunt servanda), la teoría sociológica de la validez de Petrezycky, Redbruch y el binomio de la

\footnotetext{
${ }^{12}$ N. Álvarez, «Reflexiones en torno el concepto de validez jurídica», en Revista de la Facultad de Derecho de la Universidad Complutense de Madrid, núm. 55/1979.

13 Th.M. Benditt, Law as rule and principle, Standford, Hervester Press, 1978 y N. JAREBorg, «Some competences of valid law and legal system», en Rechtstheorie, 1981. Históricamente el advenimiento del oficio judicial indica el paso de un mero orden social a un orden legal. Pero la principal fuente del Derecho entonces no era la legislación. El Derecho era fundamentalmente consuetudinario. Incluso después de un largo tiempo desde el nacimiento de los Estados con un papel legislativo bien definido, los jueces basaban sus decisiones en reglas creadas fuera del territorio del Estado (por ejemplo, la recepción del Derecho romano).
}

${ }^{14}$ M. Weber, Economía y sociedad, Fondo de Cultura Económica, México, 1987.

${ }^{15}$ U. SCARPELLI, Voz «Validità» en Gli instrumento del sapere contemporáneo, vol. II, Turín, 1985. 
seguridad-justicia, la coexistencia como justificación del Derecho en CotTa y la teoría del Diskursethik de Habermas y otras posiciones iusnaturalistas ${ }^{16}$.

El positivismo jurídico — aunque forma todo un conjunto— sí presenta algunas variantes que no voy a analizar aquí. Se habla del monismo jurídico, del dualismo jurídico y del pluralismo jurídico. Y como principios positivistas se echa mano de la teoría de la soberanía, las teorías de la norma fundamental de H. Kelsen y otras teorías como las de HART y Dworkin, de Raz y de Ost ${ }^{17}$. Mucha importancia tienen dentro del moderno pensamiento jurídico las teorías realistas y la Escuela Escandinava del Derecho pero tampoco es éste asunto que deba aquí ser expuesto ${ }^{18}$.

Sí me interesa ahora - antes de seguir adelante- detenerme un poco en la diferencia entre normativismo y positivismo jurídico, pues para algunas de las cosas que más adelante se dirán sobre la publicación de las normas jurídicas como conditio sine que non de su validez y existencia. En efecto, prescindiendo ahora de algunas clasificaciones doctrinales y en la línea tradicional, siguiendo a Modugno, hay que entender por normativismo la teoría del Derecho según la cual en general el Derecho es reducible a normas. El ordenamiento jurídico es exclusivamente un conjunto de normas. Según el normativismo, la validez de las normas (y del ordenamiento concebido como conjunto de ellas) es independiente de la efectividad o eficacia real de las mismas y consiste en su «positividad», en el sentido restringido de «ser puesta» $\mathrm{y}$ «convalidada» en el ordenamiento. En esto el normativismo se encuentra, de algún modo, como el positivismo en cuanto ambos afirman que condición necesaria y suficiente de la validez de la norma es su positividad («ser puesta») en el ordenamiento. Pero ambas teorías se diferencian, por otro lado, en cuanto, mientras para el normativismo la validez de la norma en un ordenamiento no está condicionada a ser «inherente» al mismo (pues del «ser» de cualquier modo no puede derivarse normativísticamente ningún «deber ser»), para el positivismo, sin embargo, la validez de una norma en un ordenamiento, aunque no condicionada a su «valor» deontológico (iusnaturalismo), sí lo está a «ser parte» del ordenamiento jurídico ${ }^{19}$. Por eso, desde el punto de vista filosófico-jurídico, no son idénticos el problema de la legalidad o positivi-

\footnotetext{
${ }^{16}$ R.J. Summers, «Towards a better theory of legal validity», en Rechtstheorie, 1985.

${ }^{17}$ N.M. ${ }^{a}$ López CALERA, Filosofía del Derecho, Universidad de Granada, 1985.

18 J. ItURMENDi Morales, Una aproximación a los problemas del método jurídico desde la Filosofía del Derecho, CEO, 1980.
}

${ }^{19}$ F. Modugno, Voz «Normativismo» en Enciclopedia del Diritto, tomo XVIII. 
dad y el de la normatividad. Aunque toda ley es norma jurídica, no toda norma jurídica es ley ${ }^{20}$.

\section{SANCIÓN, PROMULGACIÓN Y PUBLICACIÓN DE LAS NORMAS}

Ya he dicho anteriormente que la publicación de la norma jurídica es una conditio sine qua non de validez y existencia. Pero hay dos actos anteriores que son la sanción y la promulgación de la propia ley. Y el principio de publicidad de las normas hemos visto ya que se encuentra regulado en los artículos 9.3 y en el 91 de la Constitución, así como en los diversos Estatutos de Autonomía ${ }^{21}$ y en la propia Ley 2/1979, de 3 de octubre, del Tribunal Constitucional. Es el Rey quien sanciona, promulga y ordena publicar las leyes en el Boletín Oficial del Estado (artículo 91 CE) y los Presidentes de las Comunidades Autónomas en los términos previstos en la propia Constitución y sus respectivos Estatutos de Autonomía. Esto lo han estudiado hace cierto tiempo E. GARCía DE EnTERRÍA y TR. FERNÁNDEZ RodRíGueZ ${ }^{22}$ como es bien sabido. La sanción, en lo esencial, es el trámite que la fórmula general de todas las leyes utiliza y que ordena a todos los ciudadanos (tanto autoridades como particulares) que guarden y hagan guardar la ley de que se trate la promulgación es más que el acto de darla a conocer, el de su propia firma - la del Rey- que vendrá refrendada por la del Presidente del Gobierno o el de las Cortes Generales, según los casos y, la publicación, que también ordena el Jefe del Estado en las leyes procedentes de las Cortes Generales o los Presidentes de las respectivas Comunidades Autónomas, en los supuestos en que los mismos provengan de las Asambleas Legislativas de éstas. Por tanto, la publicación, en especial, es un requisito indispensable para la existencia, validez y eficacia de la propia norma jurídica ${ }^{23}$. Así es que este garantía aparece como consecuencia ineludible de la proclamación de España como Estado social y democrático de Derecho y se encuentra en íntima relación con el principio de seguridad jurídica consagrado en el mismo artículo 9.3 C.E. Resultarían evidentemente contrarias el principio de publicidad aquellas normas que fueren de imposible o muy difícil cono-

\footnotetext{
${ }^{20}$ H. Kelsen, Teoría general del Derecho y del Estado, UNAM, México, 1983.

${ }^{21}$ Ley Orgánica 6/1981, de 30 de diciembre, del Estatuto de Autonomía para Andalucía.

22 E. García de Enterría y T.R. Fernández Rodríguez, Curso de Derecho Administrativo, 2 vols., Ed. Civitas, Madrid, 2000.

23 J.A. Montilla Martos, Las leyes singulares en el ordenamiento constitucional español, Ed. Civitas, Madrid, 1994.
} 
cimiento (STC 117/1989, de 2 de noviembre). La publicidad de las circulares en un instrumento como el tablón de anuncios de las oficinas públicas $^{24}$ implica respecto de los funcionarios que trabajan en las mismas y a los que aquéllas pueden afectar una carga de conocimiento con las lógicas consecuencias (STC 45/1985, de 26 de marzo) ${ }^{25}$. Es evidente, por lo demás, que sólo si los destinatarios de las normas tienen la efectiva oportunidad de conocerlas, en cuanto tales normas, mediante un instrumento de difusión general que dé fe de su existencia y contenido, podrán asegurarse las posiciones jurídicas de los ciudadanos, las posibilidades de éstos de ejercer y defender sus derechos y la efectiva sujeción de los mismos y de los poderes públicos al ordenamiento jurídico. Este garantía de publicidad aparece reflejada en la Constitución en diversos preceptos, como en su artículo 91, al disponer la inmediata publicación de las leyes aprobadas por las Cortes Generales tras la sanción real (STC 169/1989, de 2 de noviembre) ${ }^{26}$.

Algún autor ha puesto de relieve el concepto de ley desde el punto de vista de las fuentes del Derecho, Para éste, los presupuestos político-constitucionales en los que se asienta la delimitación formal de ley como categoría normativa unitaria llevan aparejados la delimitación (ilimitación) material de la ley en el sistema constitucional de fuentes y su validez-existencia de acuerdo a los criterios de diferenciación apuntados, al margen del control posterior de su validez-legalidad por el Tribunal Constitucional. En el ordenamiento constitucional normativo la ley ha perdido la ilimitación característica del constitucionalismo liberal, consecuencia de la noción de soberanía ${ }^{27}$. Determinadas funciones atribuidas en la Constitución a otros órganos constitucionales deben ser respetadas (función jurisdiccional, función ejecutiva) y los distintos subordinamientos imponen límites materiales a la ley (ley estatal-ley autonómica) ${ }^{28}$. Cuando se apunta la ilimitación material me estoy refiriendo - yo mismo y el autor que esto piensa también - a una hipotética estructura vertical, el alcance material de la ley sólo puede verse afectado por el reconocimiento constitucional de reservas reglamentarias o por la difusa figura apuntada en alguna ocasión por el Tribunal Constitucional, y captada en sentido crítico por la

\footnotetext{
${ }^{24}$ J.V. Morote SARrión, El carácter normativo de las circulares e instrucciones en el Derecho español, Ed. Tirant lo Blanch, Valencia, 2002.

25 J.V. Morote SARrión, «La responsabilidad patrimonial solidaria de las Administraciones públicas en los procedimientos bifásicos», RAP núm. 154/2001.

${ }^{26}$ E. García de Enterría y T.R. Fernández Rodríguez, Curso..., op. cit.

${ }^{27}$ I. de Otto Pardo, Derecho Constitucional. Derecho de fuentes, Ed. Ariel, Madrid, 1987.

${ }^{28}$ F. Balaguer Callejón, Fuentes del Derecho, Ed. Tecnos, Madrid, 1991.
} 
doctrina de la reserva de Constitución ${ }^{29}$. La reserva reglamentaria, la restricción de un ámbito material de actuación al poder legislativo y su actuación al poder legislativo, es decir, y su actuación competencial al ejecutivo, fue planteada en el proceso constituyente. El borrador de Constitución publicado en el $B O C$ con el título de «Anteproyecto» el día 5 de enero de 1978, establecía en su artículo 37 que «las materias distintas de aquellas que caigan dentro de la esfera de la ley tendrán carácter reglamentario». Completando esta formulación, el artículo 72 incluía un listado de materias a las que calificaba de «propias» de la ley mientras que, según el artículo 79.1, «corresponde a la potestad reglamentaria del Gobierno la regulación de las materias no reservadas a la ley». Establecía, por ende, una reserva reglamentaria, siguiendo, con diferencias significativas, el modelo de la Constitución francesa de $1958^{30}$. Empero, en el texto constitucional publicado en el $B O E$ del 29 de diciembre de 1978 habían desaparecido estos preceptos y con ellos la figura reseñada. En consecuencia, en la Constitución no existe una reserva reglamentaria que sustraiga, como un hipotético reparto entre la ley y el reglamento ciertas materias a la ley para atribuirlas a la potestad reglamentaria ${ }^{31}$. El Tribunal Constitucional ha conformado, en doctrina reiterada, esta aserción ${ }^{32}$.

Ha escrito recientemente J.V. Morote SARrión —en relación, desde luego, con la publicación de las circulares e instrucciones administrativasque sólo un pequeño número de las mismas eran publicadas por la Administración, de manera que muchos ciudadanos desconocían el contenido de las mismas, si bien les eran aplicadas cuando el caso se presentaba ${ }^{33}$. Esto fue criticado por M. WALINE que mantuvo que los administrados deben entonces combatir contra un adversario enmascarado, puesto que los términos de la directriz que les ha sido aplicada no son conocidos. Ésta es una situación que recuerda algunas películas donde los personajes combaten al hombre invisible ${ }^{34}$. Una importante línea doctrinal —en opinión de J.V.

29 P. CRUZ Villalón, «¿Reserva de Constitución? Comentario al Fundamento Jurídico 4. e da STC 76/1983, de 5 de agosto, sobre la LOAPA», REDC, núm. 9/1983.

${ }^{30}$ F. GARRIDO FALla, «Las fuentes del Derecho y la reserva reglamentaria en el proyecto de Constitución», en Estudio sobre el proyecto de Constitución, CEC, Madrid, 1978.

${ }^{31}$ I. de Отто Pardo, Derecho Constitucional. Derecho de fuentes, Ed. Ariel, Barcelona, 1987.

${ }^{32}$ STC 60/1986, de 20 de mayo. La cita de la doctrina del Tribunal Constitucional en la materia es muy abundante y, no parece por lo mismo conveniente extendernos aquí en la cita pormenorizada de tales resoluciones. Puede consultarse la Colección correspondiente.

33 J.V. Morote Sarrión, Las circulares normativas de la Administración pública, Ed. Tirant lo Blanch, Valencia, 2002.

${ }^{34}$ M. WALINE, L'application des directives non publiées, RDPSP 1974. 
MOROTE SARRIÓN- ${ }^{35}$ y jurisprudencial encontraba en la falta de publicación en los periódicos oficiales un obstáculo para la inserción de la circular dentro del grupo de las normas jurídicas. La STS de 16 de junio de 1981, Ar. 2925, con relación a unas instrucciones reductoras de la discrecionalidad de la Dirección General de Comercio Interior, en las que se establecían las condiciones mínimas que deberían reunir los nuevos puntos de venta del pan, disponía: «Tales instrucciones son ineficaces como fuente del Derecho por no haber sido publicadas». Así pues, la publicación de las normas es indispensable para su existencia, validez y efectividad. Y esto llegó incluso a afectar a las circulares y las instrucciones — normas de rango jerárquico ínfimo donde las haya- que la doctrina francesa ha entendido de esta manera como ya afirmara M. WALINE hace tantos años. Por eso, el propio artículo 29 de la vieja LRJAE también preveía esta necesidad y obligatoriedad en cuanto los efectos que hubieran de surgir lo fueren ad extra, como ha puesto de relieve recientemente mi amigo el profesor valenciano J.V. Morote Sarrión. Pero es que además - como ya apunté al inicio de este estudio-, los artículos 21.1 y 37.10 de la Ley 30/1992 y de la Ley 26/1992, de 26 de noviembre, lejos de aclarar esta situación, la ensombrecen notablemente, el disponer que sólo si una disposición de rango superior así lo recoge, deberá publicarse la circular en cuestión. Por lo demás, ni la Ley 6/1992, de 14 de abril, de Organización y Funcionamiento de la Administración General del Estado, ni la propia Ley 50/1997, de 27 de noviembre (artículos 22 y sigs.), del Gobierno, han entendido oportuno regular la circular con contenido general, dentro de un precepto dedicado a la instrucción y a la orden de servicio que tiene un carácter más concreto. La circular con contenido general, esto es, aquella que interpreta una disposición legislativa y que puede afectar directamente el ciudadano no es lo que pretendía regular el legislador en este artículo. Pero tampoco, como se sabe, se las engloba dentro de las disposiciones de carácter general como hacía la antigua LRJAE, con lo que la circular queda ayuna de regulación específica. A esta nueva potestad normativa de la Administración surgida de las necesidades de normación de las complejas sociedades modernas no le ha encontrado acomodo el legislador ni entre las disposiciones de carácter general, que se regulan en el artículo 52, ni entre las instrucciones de servicio que regula este artículo 21.1. Se trata de una disposición cuyo régimen jurídico no ha estado claro históricamente en nuestro ordenamiento jurídico y respecto de la cual nuestro legislador ha optado por omitir cualquier referencia a ella, a pesar de su apabullante existencia en la práctica administrativa ${ }^{36}$.

\footnotetext{
35 J.V. Morote Sarrión, Las circulares normativas de la Administración pública, Ed. Tirant lo Blanch, Valencia, 2002.
}

${ }^{36}$ A. Catelani, Le circolari della Pubblica Administrazione, Giuffrè, Milán, 1984. 
Es curioso que, conforme al precepto citado, la regla general sea la no publicación salvo que una disposición específica así lo establezca o los destinatarios o los afectados lo requieran. Con ello, en la práctica, se deja en manos de la Administración la decisión sobre la aplicación (publicación) de este tipo de disposiciones. El precepto está redactado de tal manera que es la propia Administración la que decide sobre la publicación o no de las instrucciones y órdenes de servicio, ya que es ella la que debe realizar el análisis de conveniencia de publicar este tipo de disposiciones si estima que los efectos son trascendentes o que el número de destinatarios es relevante. Además de ello —afirma J.V. Morote Sarrión-, en el supuesto de que la Administración decida la publicación de estas disposiciones, la ley tampoco le añade efectos específicos ${ }^{37}$.

\section{NOTIFICACIÓN Y PUBLICACIÓN DE LOS ACTOS ADMINISTRATIVOS EN NUESTRO ORDENAMIENTO JURÍDICO CON ESPECIAL REFERENCIA A LA ADMINISTRACIÓN LOCAL}

Siguiendo con nuestra exposición, es conveniente conocer ahora, aunque sólo sea brevemente, los institutos de la notificación y publicación de los actos administrativos por todas las Administraciones públicas, teniendo presente también que estos actos, si son omitidos, ocasionan que no nazca la eficacia que de los mismos predica la ley ni la propia presunción de legalidad de que gozan. Incluso es dudoso que pueda hablarse de validez de los actos administrativos si no existe tal publicación o notificación, según proceda una u otra, dependiendo de lo que la ley establezca en determinadas situaciones como enseguida veremos ${ }^{38}$. Ésta es la regulación que contienen los artículos 58 a 60 de la Ley 30/1992, de 26 de noviembre, de Régimen Jurídico de las Administraciones Públicas y del Procedimiento Administrativo Común ${ }^{39}$. Resulta, pues, evidente que, para que el interesado pueda proceder al cumplimiento de un acto dictado por la Administración, es necesario: a) la notificación a los interesados de las resoluciones y actos administrativos que afecten a sus derechos e intereses (artículo 58.1 LRJ y PAC), y b) la publicación, cuando el acto tenga por destinatarios una pluralidad indeterminada de personas o cuando la Admi-

\footnotetext{
37 A. Nieto García, Los primeros pasos del Estado Constitucional, Ed. Ariel, Barcelona, 1996.

38 J.M. a Boquera Oliver, Derecho Administrativo, Ed. Civitas, Madrid, 1986 y J.A. García-TreviJano Fos, Tratado de Derecho Administrativo, Madrid, 1967.

39 J. Leguina Villa y M. SÁnchez Morón, La nueva idea de Régimen Jurídico de las Administraciones Públicas y del Procedimiento Administrativo Común, Ed. Tecnos, Madrid, 1993.
} 
nistración lo estime necesario (artículo 59.5 LRJ y PAC), así como cuando los interesados fuesen desconocidos, se ignore el lugar de la notificación o no se hubiere podido practicar por los medios normales (artículo 59.4 LRJ y PAC). Tanto la notificación como la publicación son actos independientes del que es objeto de ella. Precisamente por ser un acto ${ }^{40}$, los posibles defectos de la notificación no afectan a la validez de éste, sino a su eficacia ${ }^{41}$. Su finalidad se reduce, pues, a poner en conocimiento de las personas a quienes afecta un acto anterior ${ }^{42}$. Y, en consecuencia, la notificación determina para los afectados el comienzo de la eficacia del acto notificado (SSTS de 19 de diciembre de 1989, Ar. 9472 y 27 de febrero de 1990. Ar. 1520) ${ }^{43}$. Cuando no consta fehacientemente la fecha de notificación hay que atenerse a las manifestaciones de los interesados (STS de 23 de octubre de 1990, Ar. 8582) ${ }^{44}$.

Por lo demás, advierte un sector mayoritario de la doctrina —opinión que comparto como no podría ser de otro modo- que el fundamento de la notificación de los actos administrativos es el mismo que el fundamento de la publicación de las disposiciones generales. Si una ley ha de tenerse por no existente en tanto que no esté publicada, un acto administrativo no puede producir efectos en tanto no ha sido notificado. Como ha dicho Pi SUNYER, las disposiciones generales deben publicarse en el Boletín Oficial del Estado, las resoluciones de los expedientes deben notificarse ${ }^{45}$. La STS de 11 de noviembre de 1988 considera una exigencia del principio de tutela efectiva el deber de dar al interesado orientación procesal conforme al artículo 79 LPA (hoy 58.1 LRJ y PAC) ${ }^{46}$. La regulación contenida en la

\footnotetext{
${ }^{40}$ Hay un sector doctrinal que entiende que no estamos en presencia de un acto administrativo en el caso de las notificaciones y las resoluciones en cuanto éstas no añaden nada nuevo el acto notificado. Me encuentro en desacuerdo con ello y lo expuse con ocasión de mi comentario a un libro de NúñEz Ruzz publicado por Editorial Montecorvo y que publiqué hace ya algunos años en la Revista de Estudios Locales (CUNAL), cuyo número no recuerdo en este momento.

${ }^{41}$ STS de 19 de octubre de 1989, Ar. 7414.

${ }^{42}$ Serrano Guirado, «La notificación de los actos administrativos en la jurisprudencia, RAP núm. $1 / 1950$.

43 Agúndez, Ley de Procedimiento Administrativo, Comares, Granada, 1990.

${ }^{44}$ SSTS de 26 de febrero de 1984 y 17 de enero de 1985.

45 Pi SunYer, «El Tablón de anuncios», en Revista Moderna de Administración Pública, núm. $462 / 1949$.

${ }^{46}$ La STS de 14 de octubre de 1992, Ar. 8467, en lo que aquí importa, dice: «la finalización básica de toda notificación va enderezada a lograr que el contenido del acto llegue realmente a conocimiento de su natural destinatario, en toda su integridad sustancial y formal en una fecha indubitada susceptible de efectuar sin dificultad el cómputo del plazo previsto para que el interesado pueda actuar válidamente en defensa de su derecho».
} 
LRJ y PAC sobre notificaciones, concretamente sobre el régimen de subsanación de las notificaciones defectuosas se aparta de la normativa anterior e incurre en flagrante contradicción con el principio de tutela judicial efectiva ${ }^{47}$. Deberán notificarse, por lo demás, no sólo las resoluciones, sino cualquier otro acto administrativo que afecte a los derechos e intereses de los administrados, como interpretó la jurisprudencia, pese al texto del artículo 79.1 LPA y establece el artículo 58.1 LRJ y PAC. En cuanto a los requisitos que debe reunir la notificación, el artículo 58.2 LRJ y PAC reproduce el texto del artículo 79.2 LPA, por lo que mantiene plena vigencia la jurisprudencia recaída sobre este artículo, aunque, lamentablemente, no la conserve la dictada sobre subsanación de los defectos de los que pueda adolecer. Los requisitos objetivos que debe reunir la notificación, requisitos que asimismo debe cumplir la publicación (artículo 60.2 LRJ y PAC) son que contenga el texto íntegro del acto, que se indique si es o no definitivo en vía administrativa y la indicación de qué recursos procedan, órganos ante los que hubieran de interponerse y plazos ${ }^{48}$.

Continuando con la exposición de este apartado, el artículo 59.5 LRJ y PAC establece que la publicación, en los términos del artículo siguiente, sustituirá a la notificación surtiendo sus mismos efectos en los siguientes casos: a) cuando el acto tenga por destinatario a una pluralidad indeterminada de personas o cuando la Administración estime que la notificación efectuada a un solo interesado es suficiente para garantizar la notificación a todos, siendo, en este último caso, adicional a la notificación efectuada, b) cuando se trate de actos integrantes de un procedimiento selectivo o de concurrencia competitiva de cualquier tipo. En este caso la convocatoria del procedimiento deberá indicar el tablón de anuncios o medio de comunicación donde se efectuarán las sucesivas publicaciones, careciendo de validez las que se lleven a cabo en lugares distintos ${ }^{49}$.

\footnotetext{
47 Serrano Guirado, «La notificación de los actos administrativos en la jurisprudencia», $R A P$ núm. $1 / 1950$.

${ }^{48}$ STS de 13 de octubre de 1976.

${ }^{49}$ La STS de 22 de abril de 1980 establece lo siguiente: «A la vista de ello resulta que el propio tiempo y en defecto de la mencionada citación personal a la interesada, siempre serían exigibles para su debido cumplimiento las formalidades establecidas en estos casos por el artículo 80.3 LPA - hoy artículo 59.4 LRJ y PAC_-, cuando dispone que si los interesados en un procedimiento son desconocidos o se ignora su domicilio, la notificación se hará por medio de anuncios en el Tablón de Edictos del Ayuntamiento de su último domicilio o residencia, así como en el «Boletín Oficial del Estado» o de la provincia, mas esta forma subsidiaria de realizarse esa notificación cuando debía ser la misma persona, necesita reunir determinados requisitos formales para que surta efectos y en este caso desde luego no se han cumplido conforme resulta del propio examen de su publicación, pues entonces dicho incumplimiento dará lugar a un defecto de trámite y consiguiente indefensión, de tal modo que dicha notificación no será válida a tenor del citado artículo 48.2 de
} 
En lo que se refiere a las Corporaciones locales, la LBRL remite a la legislación del Estado en este materia, razón por la cual es aquí aplicable todo lo dicho hasta el momento y, de manera especial, lo dispuesto en los artículos 58 a 60 LRJ y PAC. Cabe destacar también aquí lo dispuesto en el Real Decreto legislativo 781/1986, de 18 de abril, texto refundido por el que se aprueban las disposiciones vigentes en materia de régimen local y, muy destacadamente, lo que establece el Real Decreto 2568/1986, de 28 de noviembre, por el que se aprueba el Reglamento de Organización, Funcionamiento y Régimen Jurídico de las Entidades locales.

\section{LA NUEVA REGULACIÓN DE LA PUBLICACIÓN DE ACTOS Y ACUERDOS DE LAS CORPORACIONES LOCALES: LOS DIARIOS OFICIALES DE LAS PROVINCIAS}

Precisamente en esta línea de pensamiento que acabo de exponer se promulga la Ley 5/2002, de 4 de abril, reguladora de los Boletines Oficiales de las provincias. Es sabido que no sólo la Ley 30/1992, de 26 de noviembre, sino también leyes sectoriales, recogen la necesidad de notificar y publicar actos de las Corporaciones locales en estos Diarios oficiales. Pero no sólo estos actos, sino que existen también casos en que se hace menester que disposiciones de rango legal o reglamentario del Estado o de las Comunidades Autónomas se vean también publicadas en dichos diarios. Además, otros organismos como las Comunidades de Regantes, los Registros de la Propiedad y los propios notarios vienen obligados a ordenar la publicación de determinados actos en los mismos. A ello hay que añadir también la obligatoria publicación de determinados actos de las sociedades mercantiles, Cajas de Ahorro popular e incluso anuncios procedentes de particulares. También — como el propio Preámbulo de la

\footnotetext{
la expresada Ley procedimental, y a fin de evitar que con ello se produzca una situación de incertidumbre para dichos interesados con los naturales perjuicios para sus legítimos intereses y que originan las pertinentes acciones impugnatorias; de todo lo cual se desprende la necesidad en el autoobjeto de esta impugnación, de que la falta de su citación personal, siempre habría deber tenido la debida y adecuada publicidad, tanto en el Tablón de Anuncios del Ayuntamiento de su último domicilio o residencia — cuando hubiere constancia de esto según ocurre en este caso—, como asimismo indistintamente de su publicación en el «Boletín Oficial del Estado» o de la provincia, con los requisitos formales pertinentes para que sea eficaz tal publicidad y especialmente con la debida determinación y concreción de los bienes afectados y la identidad de sus respectivos propietarios, datos precisos para su adecuada eficacia y validez y que en este caso resulta se omitieron al haberse prescindido de los mismos en los respectivos anuncios oficiales, por lo cual tampoco y aun a falta de citación personal que correspondía realizar, es posible tener por fehaciente dicha notificación subsidiaria, a los efectos del cumplimiento del indicado requisito formal».
} 
nueva Ley recoge- es de destacar que estos diarios oficiales son creados por Real Orden de 20 de abril de 1833, que establece la obligatoriedad de su existencia en cada provincia. Más adelante otras disposiciones regulan también esta materia. Así, destacan las Reales Órdenes de 26 de marzo de 1837, 8 de julio de 1837, 6 de abril de 1839, 4 de abril de 1840, 24 de mayo de 1846, 3 de septiembre de 1846, 21 de enero de 1849, 15 de julio de 1849 y 8 de octubre de 1856. La edición de tales boletines pasa a ser responsabilidad de las Diputaciones Provinciales a partir de las Órdenes de 8 de octubre de 1856 y 1 de agosto de 1871 . Por lo demás, la Disposición Adicional quinta de la Ley 25/1998, de 13 de julio, de modificación del régimen legal de las tasas estatales y locales y de reordenación de las prestaciones patrimoniales de carácter público, dio una nueva redacción el artículo 122 de la Ley 39/1988, de 28 de diciembre, reguladora de las Haciendas locales, que establecía que las Diputaciones provinciales seguirían editando y publicando el Boletín Oficial de la provincia, pudiendo a tal efecto establecer y exigir tasas y precios por la inserción de tasas y anuncios, es decir, por la inserción de anuncios y edictos y la suscripción y venta de ejemplares.

Por lo tanto, se sigue encomendando a las Diputaciones provinciales la edición y gestión de estos instrumentos publicitarios, debiendo las referidas Corporaciones provinciales aprobar la correspondiente ordenanza reguladora del servicio, lo que no supone novedad alguna respecto del régimen anterior. Sí resulta novedosa la posibilidad de incardinar en el Boletín Oficial de la respectiva Comunidad Autónoma los provinciales, lo que resultará obligado por la propia naturaleza de las cosas en lo que se refiere a las Comunidades Autónomas uniprovinciales ${ }^{50}$.

El propio legislador busca el título competencial en el artículo 149.1.18. ${ }^{a}$ CE, en relación con el 120.1 CE, lo que parece razonable. Precisamente, como bien señala el Preámbulo de la Ley 5/2002, de 4 de abril, el FJ 8. ${ }^{\circ}$ de la STC 233/1999, de 16 de diciembre, señala, por un lado, que la publicación de los actos jurídicos emanados de las Corporaciones locales en los Boletines Oficiales de las provincias ha de considerarse una decisión básica incardinable en la competencia atribuida al Estado por el artículo 149.1.18. ${ }^{a}$ de la Constitución, pues exige un tratamiento común y uniforme en todo el territorio del Estado que lo puede garantizar el legislador estatal y que, por otro lado, la publicación de anuncios y acuerdos en el Boletín Oficial de la provincia resulta plenamente acorde con la dimensión constitucional que a ésta atribuye el artículo 141 de la Constitución,

${ }^{50}$ R. GómEZ-FerRer Morant, La provincia, Barcelona, 1990. 
en su doble condición de agrupación de municipios y de división territorial para el cumplimiento de los fines del Estado ${ }^{50}$ entre los que hay que incluir los propios de las Corporaciones locales ${ }^{51}$ en que se organiza territorialmente el Estado como es bien conocido (artículos 137 y sigs. CE) ${ }^{52}$. Como se ve, pues, la notificación de los actos administrativos y, la publicación de otros - sobre todo de las normas con rango de ley que aquí nos interesan- son de una importancia decisiva, incluso en el terreno contractual administrativo, como pone de relieve el propio Real Decreto legislativo $2 / 2000$, de 16 de junio, por el que se aprueba el texto refundido de la Ley de Contratos de las Administraciones públicas (BOE del 21-6) ${ }^{53}$.

Este instrumento publicitario de normas jurídicas en sentido lato es un servicio público de carácter provincial, competencia propia de las Diputaciones provinciales a las que corresponde su gestión y edición. Estas Corporaciones provinciales regularán el modo y forma de gestión del periódico, su edición, distribución y venta. Para ello deberán aprobar la oportuna ordenanza reguladora del servicio ${ }^{54}$, pudiendo a tal efecto establecer y exigir tasas y precios por la inserción de anuncios y edictos ${ }^{55}$ y la suscripción y venta de ejemplares ${ }^{56}$.

La suscripción será obligatoria para los Ayuntamientos debiendo éstos abonar la tasa correspondiente con las exenciones que, en su caso, pueda establecer la Diputación provincial o la propia Comunidad Autónoma provincial o no, según ya nos consta.

La periodicidad mínima del periódico será de tres veces por semana - aunque puede ser menor- publicándose en castellano y, en su caso, en la lengua que sea cooficial en el territorio conforme a lo establecido en la legislación específica de las Comunidades Autónomas ${ }^{57}$.

\footnotetext{
${ }^{51}$ E. Roca Roca, «La comarca y los Estatutos de Autonomía», en La provincia, Granada, 1985.

${ }^{52}$ F. LLISET BoRRELl, «La incidencia de la reforma política en la Administración pública», $D A$ núm. $172 / 1976$.

${ }^{53}$ A. Iglesias Martín, «De los contratos de consultoría y de asistencia y de los servicios», Revista de Estudios Locales (CUNAL), núm. 49/2001. Por cierto que, leído con interés y cariño este estudio, no encuentro cosa diferente en el mismo que la inanidad y el puro descriptivismo como dice de este tipo de investigaciones mi amigo el profesor A. Gallego Anabitarte. Lo siento, pero nada novedoso encuentro aquí.

${ }^{54}$ Artículo 4 de la Ley 7/1985, de 2 de abril, reguladora de las Bases de Régimen Local.

${ }^{55}$ Ley 39/1988, de 28 de diciembre, reguladora de las Haciendas locales.

${ }^{56}$ Como ha venido ocurriendo hasta el momento.

${ }^{57}$ En todo caso, según me parece, la edición ha de ser bilingüe.
} 
Existe obligación de las Corporaciones provinciales de publicar cuantos disposiciones, ordenanzas, resoluciones, edictos, anuncios, actos y acuerdos de las distintas Administraciones públicas y de la Administración de Justicia deban ser insertadas en el mismo en virtud de disposición legal o reglamentaria, así como otros actos o anuncios que aquéllos les remitan, sin perjuicio de lo establecido en el artículo 11 de la Ley objeto ahora de exposición (artículo 6 LBOF). El orden de inserción corresponde al órgano competente de la Administración anunciante y será cumplimentada por la Corporación provincial siempre que cumpla los requisitos establecidos en la Ley. Los anuncios particulares podrán, asimismo, ser insertados en el BOP en los términos que se regulen en la correspondiente ordenanza provincial ${ }^{58}$.

Dice la Ley que los originales serán transcritos en la misma forma en que se hallen redactados y autorizados por el órgano remitente, sin que por ninguna causa puedan variarse o modificarse sus textos una vez éstos hayan tenido entrada en la imprenta provincial salvo que el órgano remitente lo autorice de forma fehaciente. Deberán publicarse por orden cronológico de recepción en la imprenta provincial los originales recibidos, que sólo podrá ser alterado cuando la publicación sea declarada urgente por el órgano remitente en la orden de inserción o cuando el volumen del texto para publicar así lo exija respetándose en todo caso el plazo que establece la ley. Deberá ser realizada la publicación en los quince días posteriores (días hábiles, naturalmente) al pago de la tasa correspondiente ${ }^{59}$, si éste procediera, o en su defecto, de la recepción de la orden de inserción. En caso de publicación urgente dicho plazo se reducirá a seis días hábiles. Los originales que se envíen a la imprenta provincial tendrán carácter reservado, no pudiéndose facilitar información alguna acerca de los mismos, salvo autorización expresa del órgano remitente. Si algún texto aparece publicado con erratas (Drutksprachsfehler) que alteren o modifiquen su contenido, será reproducido inmediatamente en su totalidad o en la parte necesaria con las debidas correcciones (artículo 7 LBOP).

El BOP es — siempre en dicción de la propia Ley comentada- el periódico oficial en el que se publicarán las disposiciones de carácter general y las ordenanzas, así como los actos, edictos, acuerdos, notificaciones, anuncios y demás resoluciones de las Administraciones públicas ${ }^{60}$ y de la

\footnotetext{
${ }^{58}$ I. Leguina Villa, «Principios generales del Derecho y Constitución», RAP núm. 114/1987.

${ }^{59}$ A mí no me parece adecuado supeditar la publicación de un anuncio oficial en estos boletines al abono de las tasas por tal servicio. Este supuesto puede constituir una rémora en el proceso de publicación de las normas y esto prima sobre el abono de tasa o canon alguno. Esto es más grave teniendo en cuenta que algunas Corporaciones locales demoran sus pagos en exceso.
}

${ }^{60}$ Aquí el legislador tiene un concepto lato de acto administrativo como lo tenía ZANOBINI. Cfr., 
Administración de Justicia de ámbito territorial provincial, cuando así esté previsto en disposición legal o reglamentaria. Los textos publicados en este periódico tienen la consideración de oficiales y auténticos (art. 1 LBOP).

También establece esta Ley que, a fin de comprobar la autenticidad de los documentos, los servicios correspondientes de la Diputación Provincial llevarán un registro de las autoridades y funcionarios autorizados (facultativos) para firmar la orden de inserción de los originales destinados a su publicación, en el que constarán la firma autógrafa y el nombre y cargo de la persona a que pertenezca. Los órganos correspondientes de las Administraciones públicas y de la Administración de Justicia acreditarán ante la Diputación Provincial según su normativa específica, a las personas facultadas para ordenar la inserción, así como las modificaciones que se produzcan (art. 2 LBOP). El artículo 9 LBOP se ocupa de la incorporación de los medios técnicos para la edición de estos diarios y la consulta a los mismos que será gratuita según establece la propia ley.

En los últimos preceptos, la norma que estamos analizando se ocupa del régimen económico de estos diarios oficiales. Está sujeta a pago de tasas la inserción de anuncios en el BOP con las siguientes excepciones: a) la publicación de disposiciones y resoluciones de inserción obligatoria, b) los anuncios oficiales, cualquiera que sea el solicitante de la inserción, cuando la misma resulte obligatoria, de acuerdo con una norma legal o reglamentaria, así como los edictos y anuncios de Juzgados y Tribunales cuando la inserción sea ordenada de oficio. Sin embargo — por decirlo en términos coloquiales, casi en tono de mofa o chanza-, deberán pagar quienes ordenen la inserción de: a) los anuncios publicados a instancia de particulares, b) los anuncios de licitadores de todo tipo de contratos, de acuerdo con lo establecido en su legislación específica ${ }^{61}$, c) los anuncios oficiales de la Administración de Justicia a instancia de particulares, d) los anuncios cuyo coste sea repercutible a los interesados según las disposiciones aplicables, e) los anuncios derivados de procedimientos sujetos al pago de una tasa, precio público u otro tipo de derechos económicos, y, f) los anuncios que puedan reportar, directa o indirectamente, un beneficio económico al remitente o solicitante o tuvieren contenido económico. Los anuncios que puedan y deban, además, publicarse en un diario según disposición legal o reglamentaria. Las respectivas ordenanzas reguladoras de

contrariamente, A. Gallego Anabitarte, Lecciones de Derecho Administrativo, 2 vols., Ed. Marcial Pons, Madrid, 2000-2001.

${ }^{61}$ Real Decreto legislativo 2/2000, de 16 de junio. 
las tasas podrán declarar la exención de todos o algunos de los supuestos excepcionados (artículo 11 LBOP) ${ }^{62}$.

En cuanto a la cooperación interadministrativa, establece la nueva ley que, conforme a lo Dispuesto en los artículos 55, d) de la Ley 7/1985, de 2 de abril, reguladora de las Bases de Régimen Local y 4.1, d) de la Ley 30/1992, de 26 de noviembre, de Régimen Jurídico de las Administraciones Públicas y del Procedimiento Administrativo Común, la Administración General del Estado y la de las Comunidades Autónomos prestarán, en el ámbito propio, la cooperación y asistencia activas que la Administración provincial pueda precisar para el mantenimiento y modernización del referido diario. También se establecen mecanismos de colaboración interadministrativa y entre o con particulares. Hay regímenes específicos para la Comunidad Foral de Navarra, Canarias, los Territorios Históricos y las Ciudades Autónomas de Ceuta y Melilla ${ }^{63}$. En cuanto a éstas, la ley les será de aplicación y la periodicidad de la publicación del boletín será, como mínimo, dos veces por semana, debiendo ser los órganos propios de estas dos ciudades autónomas los encargados y responsables de la gestión y edición del referido boletín oficial. Las Diputaciones Provinciales, finalmente, deberán adaptar las ordenanzas reguladores de este servicio a la nueva Ley a partir del 1 de enero del ejercicio siguiente al de la entrada en vigor de la ley ${ }^{64}$.

Como ya se ve claramente, el principio de publicidad de las normas es consustancial a la existencia misma del Estado de Derecho ${ }^{65}$. Y para ello, según ha destacado un importante sector doctrinal, tiene capital importancia el artículo 9.3 CE. En efecto, a este propósito, afirma T.R. FERNÁNDEZ Rodríguez que la indiscutible aseveración de que la Constitución como norma jurídica ${ }^{66}$ y como norma superior a todas las demás y el estableci-

\footnotetext{
${ }^{62} \mathrm{Si}$ todo lo que debe publicarse en los diarios oficiales se publicase realmente, pondríamos en peligro seguramente el propio principio de publicidad de las normas. Pero es que, además, las conocidas correcciones de errores que hoy esta norma prevé (también lo hace la Ley 30/1992, de 26 de noviembre) esconde verdaderas corruptelas y auténticos fraudes de ley contra cuyos abusos nada puede el ciudadano hacer pues ni tiene conocimiento de estas auténticas «modificaciones» ni medio de prueba para hacerlo valer (el Estado de Derecho aquí chirría sobre sus propios goznes — principio de legalidad y seguridad jurídica-). Cfr. Juan Manuel de Prada, La Tempestad, Ed. Planeta, Madrid, 1999.

${ }^{63}$ F.J. JimÉnEZ LeChugA, «El novísimo régimen autonómico de las Ciudades de Ceuta y Melilla», Revista de Estudios Locales (CUNAL) núm. 6/1995.

${ }^{64}$ M. J. Falcón y Tella, Concepto y fundamento de la validez del Derecho, Ed. Civitas, Madrid, 1994.

${ }^{65}$ L. von STEIN, Staatsrecht, Tübingen, 1980.

${ }^{66}$ E. García de EnterRía, La Constitución como norma y el Tribunal Constitucional, Ed. Civitas, Madrid, 1981.
} 
miento a su servicio de un sistema de justicia constitucional hace ya no sólo innecesaria, sino impertinente, la distinción de planos, uno jurídico y otro meramente moral, a que se vio obligado R. von IHERING en su intento de responder a esta misma cuestión ${ }^{67}$. En segundo plano, único en el que en su época tenía sentido la propia formulación de la pregunta ${ }^{68}$, ya no es moral, sino estrictamente jurídico y en él es posible llegar, mediante el recurso o la cuestión de inconstitucionalidad, es decir, tanto por vía de acción, como por vía de excepción, a la declaración de nulidad de la ley que infrinja la prohibición contenida en el artículo 9.3 de la Constitución ${ }^{69}$.

Afirma también que la generalidad de dicha afirmación (prohibición) da por supuesto igualmente que la noción de arbitrariedad que la Constitución emplea es una y la misma para todos los actos de los poderes públicos a los que se refiere y ello con independencia, naturalmente, de las peculiaridades a que pueda dar lugar su aplicación a cada clase o serie de ellos en razón de la distinta posición que cada uno de dichos poderes corresponde en el escenario constitucional. Así resulta con toda evidencia de la gestación parlamentaria del proyecto y de las palabras que su promotor, L. Martín-Retortillo Baquer ${ }^{70}$, pronunció ante la Comisión Constitucional del Senado en defensa de la enmienda que le dio vida. De lo que se trataba entonces - y de lo que, por lo tanto, se trata ahora- es de abastecer «así una pieza más en los delicados mecanismos de control», de forma que, «cuando los Tribunales, cuando los diversos órganos judiciales, cuando también el Parlamento, hayan de enfrentarse con la actuación futura (que) se sepa con claridad que está presente este principio de que los poderes públicos no actuarán arbitrariamente, lo que no significa que no puedan adoptar decisiones desiguales ante situaciones diversas también. Principio que se impone también al Parlamento pero que no recorta sus apreciaciones. Principio que, sobre todo, donde ha de tener mayor efecto, donde ha de tener mayor trascendencia, donde ha de tener mayor rigor, ha de ser en el ámbito de las Administraciones públicas» ${ }^{71}$.

\footnotetext{
${ }^{67}$ R. von IHERING, El fin en el Derecho, Buenos Aires, 1978.

${ }^{68}$ Así se desprende de un análisis detenido de la jurisprudencia del Tribunal Constitucional.

69 T.R. Fernández Rodríguez, De la arbitrariedad de la Administración, Ed. Civitas, Madrid, 1998. La pregunte es si puede el legislador comportarse arbitrariamente.

${ }^{70}$ L. Martín-Retortillo Baquer, Materiales, Ed. Akal, Madrid, 1983.

71 J.W. von Goethe, Fausto, Ed. Millenium, Madrid, 1999.
} 


\section{CONCLUSIONES}

Como siempre - quiero decir que como siempre hago en todos mis trabajos y estudios sobre el Derecho o algún aspecto atinente al mismo-, es llegado el momento de establecer algunas conclusiones o reflexiones finales sobre el trascendental asunto del principio de publicidad de las normas que tiene una trascendencia épica para los juristas ${ }^{72}$. Veamos:

Primero. El binomio secreto-publicidad del procedimiento administrativo - que inicialmente vencía de parte del primero- se inclina hoy por la obligatoriedad de publicación o notificación de los actos o resoluciones de todas las Administraciones públicas, incluso en lo que se refiere a las circulares, según ha puesto de relieve algún autor amigo mío recientemente ${ }^{73}$.

Segundo. Resulta palmario que la publicación o promulgación de la Constitución - los dos cosas, aunque no sólo- es fundamental en cuanto que fija la sujeción de todos los poderos públicos a la misma y al resto del ordenamiento jurídico. En este sentido, de especial trascendencia resultan los artículos 9.3 y 91 de la Constitución así como sus correlatos en los Estatutos de Autonomía y los artículos 58 a 60 de la Ley 30/1992, de 26 de noviembre, de Régimen Jurídico de las Aministraciones Públicas y del Procedimiento Administrativo Común, al confirmar lo dispuesto en el Título Preliminar del Código civil en cuanto al sistema de fuentes y el principio de publicidad de las normas que es correlato del principio de legalidad y del de seguridad jurídica.

Tercero. Este principio de publicidad de las normas no es un monopolio del Derecho español sino que se encuentra también recogido en los sistemas jurídicos de los Estados de nuestro entorno. Y, además, y por lo que a la Unión Europea se refiere, así lo recoge también el Tratado de Amsterdam.

Cuarto. Es evidente, además, que, por lo que se refiere a las Comunidades Autónomas, rige también este principio, de forma que sus Estatutos respectivos lo recogen ${ }^{74} \mathrm{y}$, por ende, será su Presidente quien ordene la publicación de la aludida ley autonómica, además de previamente sancio-

\footnotetext{
72 J.V. Morote Sarrión, op. cit. Sin embargo, hay que tener cuidado. Cfr. A. Malraux, La condición humana, Ed. Pocket-Eduhase, Barcelona, 1997.

${ }^{73}$ Ley Orgánica 6/1981, de 30 de diciembre, del Estatuto de Autonomía para Andalucía.

${ }^{74}$ BOE núm. 82, de 5 de abril de 2002.
} 
narla y, promulgarla, para su inserción en el Boletín autonómico. En ocasiones - cuando de leyes se trate, lógicamente- hay que publicarlas también en el Boletín Oficial del Estado.

Quinto. Y, por lo que a las Corporaciones locales se refiere, también resulta evidente que, al estar provistas de la potestad reglamentaria (artículo 4 LBRL), sus ordenanzas y reglamentos han de ser publicados, como mínimo, en el correspondiente Boletín Oficial de la provincia o en el autonómico uniprovincial. Esto es lo que ha venido a regular la Ley $5 / 2002$, de 4 de abril ${ }^{75}$, aunque la verdad es que no es muy novedosa esta ley y la sola invocación de su existencia en la Ley de 27 de noviembre de 1997 hubiese sido suficiente, dejando el resto a la reglamentación de las Comunidades Autónomas y las propias Diputaciones provinciales.

Sexto. En cuanto a los actos y acuerdos de las Corporaciones locales ${ }^{76}$, cabe decir que siguen el régimen general hasta ahora conocido. Por tanto, regirán de forma preferente, no subsidiariamente ni supletoriamente, la Ley 30/1992, de 26 de noviembre (arts. 58 a 60) y lo dispuesto en las leyes autonómicas - en cuanto a especialidades- con lo establecido en el Real Decreto 2568/1986, de 28 de noviembre, por el que se aprueba el Reglamento de Organización, Funcionamiento y Régimen Jurídico de las Entidades locales. Hay que advertir de que este último contiene algunas antinomias y es ilegal en algún extremo, según he comprobado, pero en cuyo detalle no entraré.

Es necesario erradicar esa vieja práctica según la cual las Administraciones públicas utilizan las correcciones de errores (a veces hay varias correcciones de un mismo texto) para introducir nuevas situaciones o cambiar de rumbo determinada parte de la realidad social que configuran, lo que supone a todas luces un fraude de ley ${ }^{77}$.

Aunque estas materias resultan sin duda áridas y espesas no sólo para juristas, sino también para profanos, es indudable, de otra parte, la trascendencia práctica que su recto entendimiento encierra. Otra cosa es que

\footnotetext{
${ }^{75}$ F.J. Jiménez LechugA, «Autonomía local y órganos necesarios de las Corporaciones locales en España», Revista de Estudios Locales (CUNAL), núm. 56/2002.

${ }^{76}$ F. de Castro y Bravo, El negocio jurídico, Madrid, 1991 y M. Albaladejo García, Derecho civil, 5 vols., Ed. Bosch, Barcelona, 1989.

77 J. Jiménez Lozano, Las sandalias de plata, Ed. Seix Barral, Barcelona, 1999; M. Unamuno, La tía Tula, Biblioteca El Mundo, Madrid, 2001; P. BAroja, Las inquietudes de Shanti Andía, Biblioteca El Mundo, 2001; S. Puértolas, La rosa de plata, Planeta, 1999; F. Umbral, Madrid (tribu urbana), Planeta, 2000; A. VÁzquez Figueroa, León Bocanegra, Ed. Orbial 1999 y J.M. de PRADA, La tempestad, Planeta, 1999.
} 
de vez en cuando haya que leer alguno de nuestros recientes autores con una obra literaria valiosa. Porque todo no va a ser Derecho.

\section{BIBLIOGRAFÍA}

García de EnTERRía, E., Jueces y seguridad jurídica en un mundo de leyes desbocadas, E. Civitas, Madrid, 1999.

Álvarez, N., «Reflexiones en torno el concepto de validez jurídica», en Revista de la Facultad de Derecho de la Universidad Complutense de Madrid, núm. 56/1979.

Garzón Valdés, E., Algunos modelos de validez normativa, México, 1980.

Falcón y Tella, M. J., El concepto y fundamento de la validez del Derecho, Ed. Civitas, Madrid, 1994.

Pattaro, E., Filosofía del Derecho. Ciencia jurídica, Ed. Reus, Madrid, 1980.

Albaladejo García, M., Derecho civil, 5 vols., Ed. Bosch, Barcelona, 1989.

Delgado Pinto, J., La validez del Derecho como problema en la Filosofía jurídica, México 1980.

Weber, M., Economía y sociedad, Fondo de Cultura Económica, México, 1987.

Otto Pardo, I. de, Derecho Constitucional. Derecho de fuentes, Ed. Ariel, Barcelona, 1987.

GaRrido Falla, F., «Las fuentes del Derecho y la reserva reglamentaria en el proyecto de Constitución», en Estudio sobre el proyecto de Constitución, CEO, Madrid, 1978.

Summers, R.J., «Towards a better theory of legal validity», en Rechtstheorie, 1985.

García de Enterría, E. y Fernández Rodríguez, T. R., Curso de Derecho Administrativo, 2 vols., Ed. Civitas, Madrid, 2000. 
Morote Sarrión, J.V., Las circulares normativas de la Administración pública, Ed. Tirant lo Blanch, Valencia, 2002.

Kelsen, H., Teoría general del Estado y del Derecho, UAM, México, 1983.

Balaguer Callejón, F., Fuentes del Derecho, Ed. Tecnos, Madrid, 1991.

Cruz Villalón, F., «¿Reserva de Constitución? Comentario a1 Fundamento Jurídico $4 .^{\circ}$ de la STC 76/1983, de 5 de agosto, sobre la LOAPA», REDC núm. 9/1983.

Montilla Martos, J.A., Las leyes singulares en el ordenamiento constitucional español, Ed. Civitas, Madrid, 1994.

Modigno, F., «Voz normativismo», en Enciclopedia del Diritto, tomo XVIII.

WALINE, M., L'application des directives non publiées, RDPSP, 1974.

Leguina Villa, J. y SÁnchez Morón, M., La nueva Ley de Régimen Jurídico de las Administraciones Públicas y del Procedimiento Administrativo Común, Ed. Tecnos, Madrid, 1993.

Nieto García, A., Los primeros pasos del Estado Constitucional, Ed. Ariel, Barcelona, 1996.

Gómez-Ferrer Morant, R., La provincia, Barcelona, 1990.

Leguina Villa, J., «Principios generales del Derecho y Constitución», RAP núm. 114/1987.

Roca RocA, E., «La comarca y los Estatutos de Autonomía», en La provincia, Granada, 1985.

JimÉnez LeChuga, F.J., «El novísimo régimen autonómico de las ciudades de Ceuta y Melilla», Revista de Estudios Locales (CUNAL) núm. 6/1995.

STEIN, L. von, Staatsrecht, Tübingen, 1980.

Castro y Bravo, F., El negocio jurídico, Madrid, 1991.

Goethe, J.W. von, Fausto, Ed. Millenium, Madrid, 1999.

Martín-Retortillo Baquer, L., Materiales, Ed. Akal, Madrid, 1983. 
JiMÉnEz LeChUGA, F.J., «Autonomía local y órganos necesarios de las Corporaciones locales en España», Revista de Estudios Locales (CUNAL) núm. 56/2002.

IHERING, R. von, El fin en el Derecho, Buenos Aries, 1978.

VÁzQuEz FigueroA, A., León Bocanegra, Ed. Orbis, Madrid, 1999.

Prada, J.M. de, La tempestad, Planeta, 1999.

Beladiez Rojo, M., Los principios jurídicos, Madrid, 1994.

WolfF, E., El problema del Derecho natural, 1961.

Vedel, G. y Devolvé, P., Droit Administratif, 2 vols., PUF, Paris, 1992. 